\title{
A Real-Time Load Distribution Method of Hydro-Thermal Power Grid Based on Working Conditions Self-Matching
}

\author{
Fang Chen ${ }^{1}$, Jianzhong Zhou ${ }^{1, a}$ and Xuemin Wang ${ }^{1}$ \\ ${ }^{1}$ School of Hydropower and Information Engineering, Huazhong University of Science and Technology, Wuhan, \\ 430074, P R China
}

\begin{abstract}
Short-term hydro-thermal power optimal dispatch is a classical problem. Traditional scheduling methods cannot meet the requirements of different dispatch periods separately, and can hardly ensure the safety operation of cascade hydropower stations and reduce wasting water. So the problem how to ensure the safety operation of power grid and the rational utilization of water resources should be settled urgently. In order to solve the problem, a realtime load distribution method of hydro-thermal power grid based on working conditions selfmatching is proposed in this paper. In the proposed method, working conditions self-matching is proposed to meet the requirements of different dispatch periods separately for ensuring the efficiency and economy of the power grid. Finally, the proposed method is applied to Sichuan power grid to verify its feasibility and effectiveness. Compared to traditional scheduling methods, the proposed method not only has excellent performance in the utilization of water resources but also can meet all constrains of each scheduling period, which provides a new method to solve the real-time load distribution of hydro-thermal power grid.
\end{abstract}

\section{Introduction}

The real-time load distribution of hydro-thermal power system [1]refers to distribute the load among hydropower and thermal power stations according to certain economic operation[2] mode. However, when the load changes, dispatchers usually make real-time load adjustment based on their scheduling experience. The adjustment plan which they made is always not conducive to the economic dispatch of cascade hydropower stations. There are some research on short-term hydro generation scheduling of Xiluodu-Xiangjiaba cascade hydropower stations and Three Gorges-Gezhouba[3, 4] cascaded hydropower plants. The results are excellent and powerful. But they neglected the adjustment ability of thermal power and did not take the security and stability operation of the power grid fully into consideration. So a new real-time load distribution method of hydro-thermal power grid, which can not only meet all constrains but also ensure the efficiency, economy and security of the power grid, is needed urgently.

\section{Real-time Load Distribution of Cascade Hydropower Stations}

\footnotetext{
${ }^{a}$ Corresponding author : 1103448274@qq.com

(C) The Authors, published by EDP Sciences. This is an open access article distributed under the terms of the Creative Commons Attribution License 4.0 (http://creativecommons.org/licenses/by/4.0/).
} 
The real-time load distribution of hydro-thermal power grid can be divided into two parts. The realtime load distribution among hydropower stations and thermal power stations is one part. The realtime load distribution of cascade hydropower stations is another part. The real-time load distribution of cascade hydropower stations is aimed to maximize the total energy storage of cascade hydropower stations over the current scheduling period, while meeting kinds of equality and inequality constrains.

\subsection{Objective Function}

$$
o b j=\max \sum_{i=1}^{M}\left(Z_{i}^{\text {up }}-Z_{i}^{\text {down }}\right)\left(Q_{i}^{\text {in }}-Q_{i}^{\text {out }}\right)
$$

The above formula is aimed to maximize the total energy storage of cascade hydropower stations over the current scheduling period. Where obj is the total energy storage of the hydropower stations over the current scheduling period; $\mathrm{M}$ is the number of hydro plants; ${ }_{i}^{\text {up }}$ is the average upstream water level of the i-th hydro plant over the current scheduling period; ${ }_{i}^{{ }^{\text {down }}}$ is the average downstream water level of the i-th hydro plant over the current scheduling period; $Q_{i}^{\text {in }}$ is the inflow of the i-th hydro plant over the current scheduling period; $Q_{i}^{\text {down }}$ is the outflow of the i-th hydro plant over the current scheduling period.

\subsection{Constrains}

In the process of real-time load distribution, various complex equality and inequality constrains, such as restrictions of water levels, outputs and hydraulic connections, should be taken into account for restricting the total energy storage optimization. The constraints are described as follows:

(1) Water level constrains

$$
Z_{i, j}^{\min } \leq Z_{i, j} \leq Z_{i, j}^{\max }
$$

In the above inequality, ${ }^{Z_{i, j}}$ is upstream water level of the i-th hydro plant at the end of the j-th period; ${ }_{i, j}^{\min }$ and ${ }^{Z_{i, j}^{\max }}$ represent the lower and upper water level limits of the i-th hydro plant of the j-th period, separately.

(2) Output constrains

$$
N_{i, j}^{\min } \leq N_{i, j} \leq N_{i, j}^{\max }
$$

In the above equation, $N_{i, j}$ is output of the $\mathrm{i}$-th hydropower station in the $\mathrm{j}$-th period; ${ }^{N_{i, j}^{\min }}$ and ${ }^{N_{i, j}^{\max }}$ represent the minimum and maximum output limits of the i-th hydropower station in the $\mathrm{j}$-th period, separately.

(3) Water discharge constrains

$$
Q_{i, j}^{\min } \leq Q_{i, j} \leq Q_{i, j}^{\max }
$$

In the above equation, $Q_{i, j}$ is water discharge of the $\mathrm{i}$-th hydropower station in the $\mathrm{j}$-th period; $Q_{i, j}^{\min }$ and $Q_{i, j}^{\max }$ represent the minimum and maximum water discharge limits of the i-th hydropower station in the $\mathrm{j}$-th period, separately.

(4) Hydraulic connection

$$
I_{i, j}=\sum_{l \in \Omega_{i}} Q_{i, j}+B_{i, j}
$$

In the above equation, ${ }_{i, j}$ and ${ }^{B_{i, j}}$ represent the inflow and local inflow of the i-th hydropower station in the $\mathrm{j}$-th period, separately; ${ }_{i, j}$ is water discharge of the 1-th hydropower station in the $\mathrm{j}$-th period; $\Omega \mathrm{i}$ is upper hydro plants set of the $\mathrm{i}$-th plant.

(5) Water balance equation 


$$
V_{i, j}=V_{i, j}{ }^{0}+\left[I_{i, j}-Q_{i, j}\right] \Delta t
$$

In the above equation, $V_{i, j}^{0}$ is the storage of the $\mathrm{i}$-th hydropower station at the beginning of the j-th period; $V_{i, j}$ is the storage of the i-th hydropower station at the end of the j-th period; ${ }_{i, j}$ and ${ }^{Q_{i, j}}$ are the inflow and water discharge of the $\mathrm{i}$-th hydropower station in the $\mathrm{j}$-th period, separately; $\Delta \mathrm{t}$ is interval of scheduling term.

\section{Strategies of HTPC and WCSM}

The hydro-thermal power combined adjustment (HTPC) is proposed to enhance the safety and stability operation of the power grid. When the total load decreases, thermal power output reduces firstly. However when the load increases, hydropower output raises in flood or falling off season and thermal power output raises in dry or impounding season firstly. Different scheduling periods have different inflow and water level requirements. If scheduling according to the same rules, it will not only lead to the waste of water resources, but also a certain threat to the safety operation of plants. Then different strategies are proposed based on each scheduling period, which is called working conditions self-matching (WCSM). Differential evolution (DE) $[5,6]$ is suitable to solve the load optimal allocation model of cascade hydropower stations in chapter 2 . The detailed illustrations are as follows:

Assuming that $\Delta P$ is the $\mathrm{D}$-value between the real-time load and the planned load.

\subsection{Strategies for Flood Seasons When the Load Increases}

In the flood season[7], the inflow is plentiful. In order to ensure the safety operation of the hydropower plants, the upstream water level can rise in a small range only when the plants have spilled water. This measure allows the reservoir to save more energy. Otherwise, the upstream water level keeps unchanged.

At first, if there is no spilled water and the hydropower output has been the maximum output under the current conditions, the hydropower output keeps unchanged, and the increment of thermal power output is $\Delta P$. And if there is no spilled water and the hydropower output has not reached the maximum output under the current conditions, the upstream water levels keep unchanged and just adjust the load distribution to reach the maximum output under the current conditions. Furthermore, if there is lots of spilled water and the hydropower output has been the maximum output under the current conditions, the upstream water level can rise to the allowable maximum to storage water until there is no spilled water. Then the maximum hydropower output $P_{s}^{\max }$ under the current conditions can be obtained by checking the table which describes the relationship between the maximum output and the inflow. And then the maximum increment of hydropower output $\overline{\Delta P}_{s}$ can be calculated according to formula (10). If $\overline{\Delta P}_{s}$ is more than or equal to $\Delta P$, the increment of hydropower output is $\Delta P$ and the thermal output remain unchanged. Otherwise, the increment of hydropower output is $\overline{\Delta P}_{s}$ and the increment of thermal power output ${ }^{\Delta P_{h}}$ can be calculated according to formula (11). Meanwhile, the thermal power output turns to $P_{h}^{\max }$ if it cannot meet formula (12). And the increment of thermal power output turns to $U R_{h}$ if it cannot meet formula (13). Then the adjusted outputs of cascade hydropower stations and thermal power stations are obtained. Finally, according to Section 2 and 3, the real-time load distribution of hydro-thermal power grid can be completed.

$$
\begin{aligned}
& \overline{\Delta P}_{s}=P_{s}^{\max }-P_{s} \\
& \Delta P_{s}+\Delta P_{h}=\Delta P
\end{aligned}
$$




$$
\begin{gathered}
\alpha P_{h}^{\max } \leq P_{h} \leq P_{h}^{\max } \\
D R_{h} \leq P_{h}^{t}-P_{h}^{t-1} \leq U R_{h}
\end{gathered}
$$

$P_{s}$ is the current hydropower output; ${ }^{P_{s}^{\max }}$ is the maximum hydropower output under the current conditions; $\overline{\Delta P}_{s}$ is the maximum increment or decrement of hydropower output; $\overline{\Delta P}_{h}$ is the maximum increment or decrement of thermal power output; ${ }^{P_{h}}$ is the current thermal power output, ${ }_{h}{ }^{\max }$ is the maximum thermal power output, $U R_{h}$ is the maximum increment of thermal power output, and $D R_{h}$ is the maximum decrement of thermal power output. $\alpha$ is a constant between 0 and 1 . It is a compression ratio of thermal power output.

\subsection{Strategies for Falling off Seasons When the Load Increases}

In the falling off season, when the total load increases, the upstream water level of hydropower stations can fluctuate within a certain range. If the inflow is plentiful, the upstream water level can rise to increase the storage of energy. Otherwise, the upstream water level can drop to increase the output. If the hydropower output cannot increase under the current conditions, the hydropower output keep unchanged, and the increment of thermal power output is $\Delta P$. Otherwise, the upstream water level at the end of the period $Z_{1}$ can be calculated according to the planned load and forecasted inflow.

\subsection{Strategies for Impounding Seasons or Dry Seasons When the Load Increases}

In impounding season or dry season, the inflow is insufficient. So it is necessary to save water. When the total load raises, increasing thermal power output can save water to ensure the hydropower stations run at high water levels. Thus the overall principle is that thermal power output increases firstly.

\subsection{Strategies for the Load Decreases}

When the total load decreases, decreasing thermal power output can reduce waste water to improve the efficiency of hydropower and enhance the safety and stability of cascade hydropower stations. Furthermore reducing coal consumption is conducive to environmental protection. So the overall principle is that thermal power output decreases firstly. According to formula (12) and (13), the maximum decrement of thermal power $\overline{\Delta P}_{h}$ can be calculated. If $\Delta P$ is less than $\overline{\Delta P}_{h}$, the decrement of thermal power output is $\Delta P$, and the hydropower output keep unchanged. Otherwise, according to formula (10) and (11), the decrement of thermal power output $\Delta P_{h}$ and the decrement of hydropower power output $\Delta P_{s}$ can be calculated. Then the adjusted output of cascade hydropower stations and thermal power stations are obtained. Finally, according to Section 2 and 3, the real-time load distribution of hydro-thermal power grid can be completed.

\section{Case Study}

For the Xiluodu-Xiangjiaba cascade hydropower stations, the load is assigned by the dispatching centre of power grid. And the load is made up of two parts, one part is assigned by State Grid, another part is assigned by Southern Power Grid. The fluctuation of the load is generated mainly from the Sichuan Power Grid. Meanwhile, the load assigned by Southern Power Grid is provided by the right bank units of Xiluodu. And the load assigned by State Grid is provided by Xiangjiaba and the left bank units of Xiluodu. The case took 15 minutes as a scheduling period. Assuming that the thermal power output of Sichuan Power Grid has been the minimum. The basic parameters of Xiluodu and Xiangjiaba is shown in Table 1. The real-time load and planned load is shown in Fig.1 and Fig.2. 
Table 1. The basic parameters of Xiluodu and Xiangjiaba.

\begin{tabular}{|c|c|c|c|c|c|c|}
\hline Reservoir & $\begin{array}{c}\text { Normal water } \\
\text { level }(\mathrm{m})\end{array}$ & $\begin{array}{c}\text { Dead water } \\
\text { level }(\mathrm{m})\end{array}$ & $\begin{array}{c}\text { Initial water } \\
\text { level }(\mathrm{m})\end{array}$ & $\begin{array}{c}\text { Water level } \\
\text { amplitude }(\mathrm{m})\end{array}$ & $\begin{array}{l}\text { Regulation } \\
\text { storage }\left(\mathrm{m}^{3}\right)\end{array}$ & $\begin{array}{c}\text { Installed capacity } \\
(\mathrm{MW})\end{array}$ \\
\hline Xiluodu & 600 & 540 & 580 & 0.5 & $64.6 \times 10^{8}$ & 13500 \\
\hline Xiangjiaba & 380 & 370 & 375 & 1 & $9.03 \times 108$ & 6400 \\
\hline
\end{tabular}

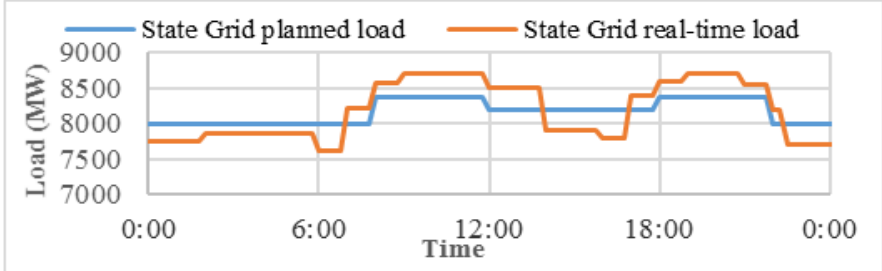

Figure 1. The Load of State Grid.

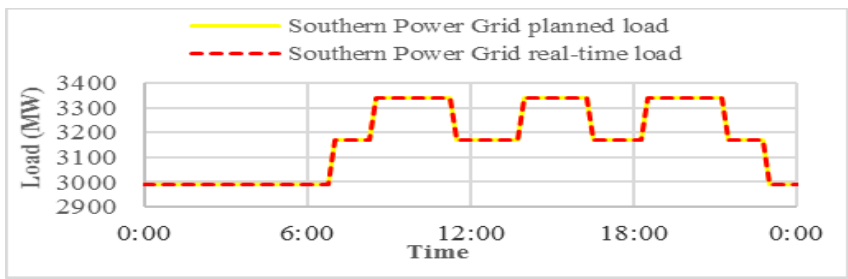

Figure 2. The Load of Southern Power Grid.

And the results are shown in Fig.3 and Fig.4.

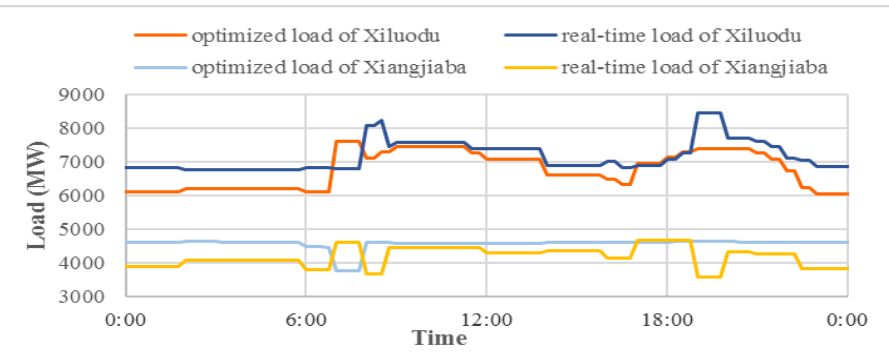

Figure 3. The Load of Xiluodu and Xiangjiaba.

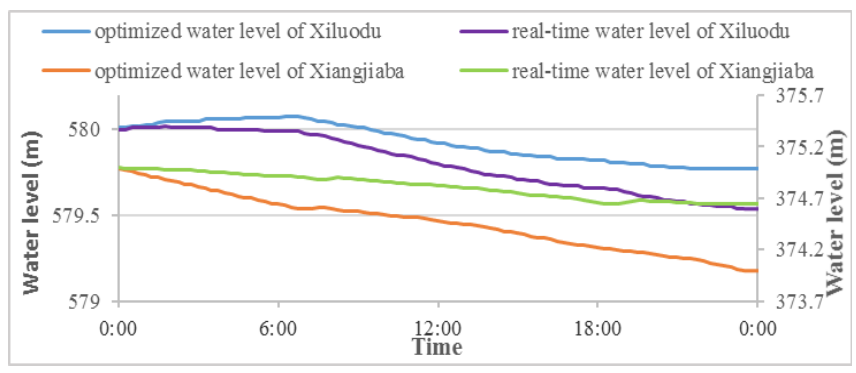

Figure 4. The Water Level of Xiluodu and Xiangjiaba.

According to Fig.3 and Fig.4, in the day, the total water consumption of Xiluodu was $2.61 \times 108 \mathrm{~m}^{3}$, and the total water consumption of Xiangjiaba was $2.24 \times 108 \mathrm{~m}^{3}$. During the 96 scheduling periods, the real-time energy storage was $27.367 \times 10^{8} \mathrm{kWh}$, and the optimized energy storage was $27.797 \times 10^{8} \mathrm{kWh}$. So the energy storage increased $0.43 \times 10^{8} \mathrm{kWh}$ in the day. Furthermore, the two hydropower stations both have no waste water all day. Moreover, the variation of Xiangjiaba water 
level was less than $1 \mathrm{~m}$, then the optimized results cannot have influence on the economic operation of the next day.

\section{Conclusions}

The results of Case study show that the proposed method can obtain more total energy storage in falling off season. And the comparison between the optimized outputs and actual outputs shows that the proposed strategies can be more in line with the requirements of the grid and have effective utilization of water resource while ensuring the security and stability of the system. Finally, the proposed HTCA and WCSM can generate reasonable load distribution as well as meet all kinds of hydraulic and electrical constraints. And the two proposed strategies have effective utilization of water resource while ensuring the security and stability of the power grid.

\section{References}

1. S.E. Humphris, M.K. Tivey, M.A. Tivey. The Trans-Atlantic Geotraverse hydrothermal field: A hydrothermal system on an active detachment fault. Deep Sea Research Part II Topical Studies in Oceanography. (2015)

2. A.H. Elbatran, O.B. Yaakob, Y.M. Ahmed, H.M. Shabara. Operation, performance and economic analysis of low head micro-hydropower turbines for rural and remote areas: a review. Renewable \& Sustainable Energy Reviews. 43 (2015) 40-50

3. L. Mo, P. Lu, C. Wang, J. Zhou. Short-term hydro generation scheduling of Three GorgesGezhouba cascaded hydropower plants using hybrid MACS-ADE approach. Energy Conversion \& Management. 76 (2013) 260-73

4. W. Chao, J. Zhou, L. Peng, Y. Liu. Long-term scheduling of large cascade hydropower stations in Jinsha River, China. Energy Conversion \& Management. 90 (2015) 476-87

5. M. Hou, C. Luo, L. Wei, L.I. Peng. Study on short-term hydrothermal scheduling based on differential evolution. Power System Protection \& Control. (2015)

6. J. Brest, A. Zamuda, B. Bošković. Adaptation in the Differential Evolution. Adaptation Learning \& Optimization. (2015)

7. J.X. Yuan, D.Q. Zhang, Z. Zhang. Study on Optimal Operation for Recession Flood of Hydropower Reservoir. South-to-North Water Transfers and Water Science \& Technology. (2007) 